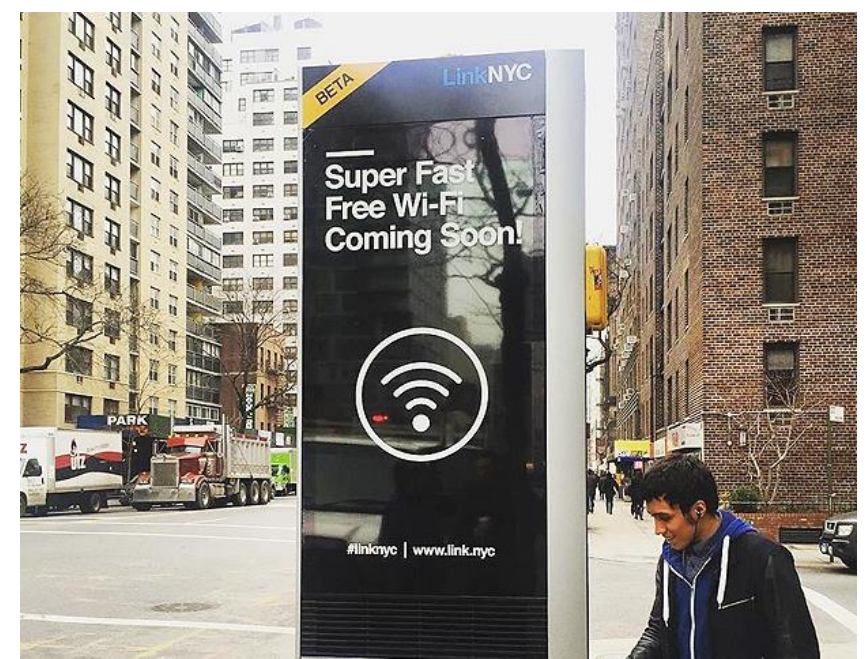

\title{
Linhas, redes e filamentos: no fio do discurso da cidade
}

Lines, networks and filaments in the city discourse wire

Cristiane Dias ${ }^{1}$

\section{Resumo:}

Esse artigo tem como objetivo mostrar, a partir do modo como os dispositivos tecnológicos estão incorporados à cidade, como as formas de circulação ou interdição à mobilidade, ressignificam o espaço urbano e aquilo que lhe é próprio: os sujeitos e os movimentos. Como a conectividade passa a ter papel fundamental na forma de organização social dos sujeitos. Forma de organização que tema colaboratividade como característica. Essas questões permeiam a escrita desse artigo sob a perspectiva teórica e analítica da Análise de Discurso, que considera o confronto entre o simbólico e o político.

Palavras-chave: mobilidade; conectividade; relações sociais; discurso; cidade; digital.

\begin{abstract}
:
This article proposes to show, from the way the technological devices are part of the city, how the forms of circulation or mobility interdiction resignify urban space and what is proper to it: the subject and the movements. How connectivity has now a key role in the social organization of the subject. A social organization that has colaborativity as feature. This article discuss these questions under the theoretical and analytical perspective of discourse analysis, which considers the confrontation between the symbolic and political.
\end{abstract}

Keywords: mobility; connectivity; social relations; discourse; city; digital

1 Pesquisadora do Laboratório de Estudos Urbanos - Nudecri da Unicamp. E-mail: crisdias.unicamp@gmail.com Endereço: Labeurb - Laboratório de Estudos Urbanos Unicamp/Cocen / Nudecri Caixa Postal 6166 Campinas/SP - Brasil. CEP: 13083-892 


\section{Introdução}

Quando pensamos a cidade, não a pensamos apartada dos dispositivos e tecnologias que a constituem. Porém, diferentemente do discurso do urbano que se ancora na organização da cidade e do social a partir de um imaginário da eficácia desses dispositivos e tecnologias para a vida dos sujeitos e para uma administração do modo de circulação no espaço, nosso objetivo é compreender a maneira como dispositivos tecnológicos produzem uma certa ordem da cidade, determinada pelo discurso digital, ressignificando as relações em sua forma social a partir da eficácia simbólica dos objetos digitais na vida e no cotidiano dos sujeitos, naquilo que diz respeito às suas práticas e ao seu modo de existência histórica.

Buscamos compreender onde a tecnologia falha em seu imaginário de eficácia técnica e pragmática para dar lugar ao conflito, à des-ordem do urbano, ao real da cidade em sua constituição pelo digital. Onde a constituição do urbano pelo digital vem perturbar a organização e instaurar a diferença ${ }^{2}$, uma outra ordem para o dizer.

Para tanto, considero a conectividade a matéria-prima do espaço urbano contemporâneo, da qual deriva, por uma relação material, outras formas de mobilidade, pelo digital, e de organização social, pela colaboratividade.

Quando falo em conectividade, refiro-me tanto à conectividade entre os objetos, entre os objetos e sujeitos quanto à relação dos sujeitos entre si. O que conecta os sujeitos são as redes, as linhas, os filamentos de fibra ótica, que vão traçando itinerários, percursos e sentidos por vias digitais no espaço urbano.

Mas esses percursos são também traçados por muitas outras camadas da cidade e da mobilidade, significantes do espaço constituído pela tecnologia. São as linhas de trem, de ônibus, de metrô, também as linhas de telefone, as faixas de pedestre, as ciclovias. Todas elas constituem a cidade e o sujeito em conexão e são também, transversalmente ressignificadas pelo digital.

Em 04/01/2016, o caderno Tec da Folha de São Paulo, publica notícia sobre a troca dos orelhões, em Nova Iorque, por pontos de internet wi-fi gratuita.

\footnotetext{
2 Essa reflexão está pautada nos trabalhos de Eni Orlandi (1999, 2004), que traz as noções de ordem e organização para pensar a cidade, bem como formula, a partir daí a noção de "falas desorganizadas". Para a autora, "as falas desorganizadas são vestígios, indícios, desses pontos em que a cidade poderia se dizer, em seu real concreto" (2004, p. 69).
} 


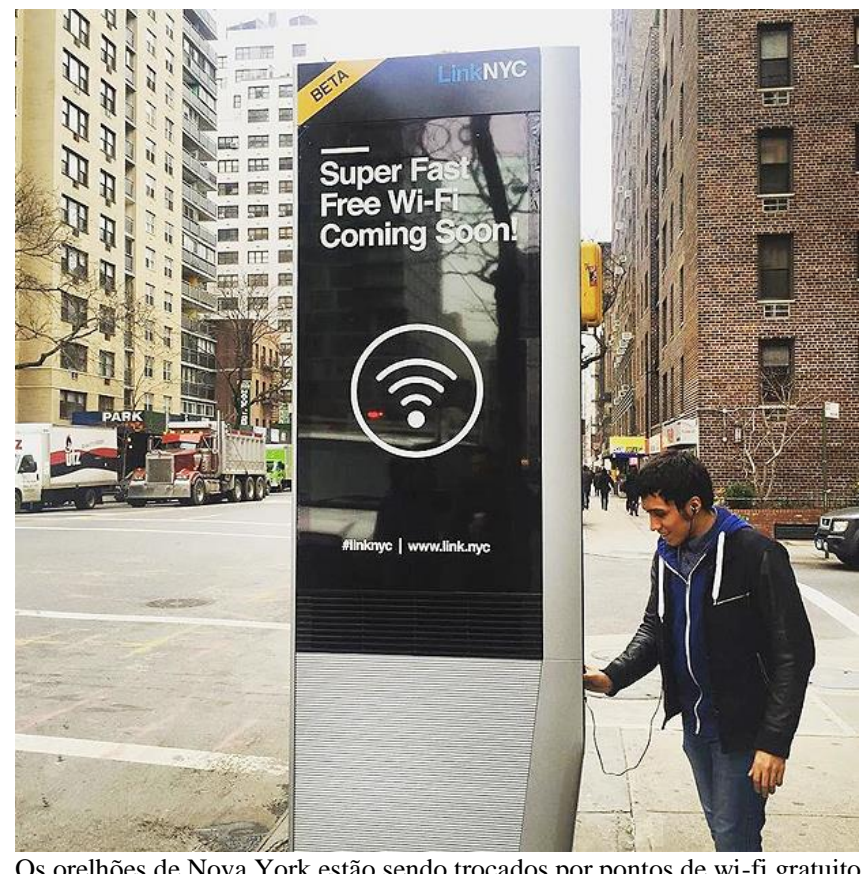

Figura 1 - Disponível em: http://www1.folha.uol.com.br/tec/2016/01/1725628-nova-york-comeca-atrocar-orelhoes-por-pontos-de-wi-fi-gratuitos.shtml Acesso em 02/10/2016

A cidade de Nova York começou a trocar, no fim do mês de dezembro, os velhos orelhões, localizados por toda parte, por pontos de internet wi-fi gratuita.

A tecnologia dos orelhões é substituída por pontos de acesso à internet sem fio. Outras formas de conexão. Não se trata de olhar apenas para uma simples substituição de uma tecnologia por outra, pois nesse gesto está implicado uma ressignificação mais ampla da cidade e do sujeito no espaço urbano, não se trata apenas da organização e da eficácia técnica desses recursos ou objetos, mas trata-se, antes, de uma ordem do discurso da cidade, constituída pela mobilidade, pelas relações sociais, e pela tecnologia.

Os orelhões continuam, de qualquer modo, produzindo sentido pelo interdiscurso, ainda que sejam substituídos por outras tecnologias ou funcionalidades.

Em São Paulo, um projeto experimental foi lançado neste mês de outubro de 2016. O projeto "conecta" os cerca de 25 mil orelhões espalhados pela cidade e o transporte coletivo através do uso de dados abertos. Segundo notícia do projeto divulgada no Olhar Digital: 


\begin{abstract}
o algoritmo desenvolvido combina as informações online em tempo real sobre horários e itinerários dos ônibus que circulam na cidade com o mapeamento geográfico de todos os orelhões em funcionamento na capital. (...) Para quem não tem internet no celular ou simplesmente não tem um smartphone, basta ligar para o número 0800887 0878, claro, a partir de um orelhão. Uma gravação automática atende a ligação enquanto o robô por trás da operação entra em ação. Em questão de segundos, o sistema identifica a localização geográfica do orelhão de onde está sendo feita a chamada e, em seguida, informa o tempo de chegada dos ônibus no ponto mais próximo dali... ${ }^{3}$
\end{abstract}

A conectividade produzindo efeitos na mobilidade urbana, nos modos de viver a cidade.

Orelhões por $w i$-fi, outras redes, mas também as redes de metrô, de lojas são afetadas pelo digital. Sinais de trânsito. Sinal de celular, sinal de internet. São conectividades. Traçados urbanos. Texturas do urbano. Conexões do urbano: linhas, faixas, redes, sinais. Tudo desemboca no digital por meio de sistemas e circuitos integrados. E pelos discursos. Efeitos de sentidos produzidos por essas conectividades entre sujeitos.

Assim, pergunto, que direção para os sentidos da cidade? Em frente? Proibido? Segurança? Velocidade? Conectado? Esses sentidos e direções possíveis são constitutivos do que hoje chamamos mobilidade e que constituem a cidade como uma cidade conectada, uma vez que são as redes de conectividade que gerem a cidade em sua organização, por meio de sistemas digitais de comunicação e informação que regulam as práticas comerciais, financeiras, os comportamentos, os itinerários, a segurança, etc. Mas são também as redes de conectividade que produzem uma ordem discursiva, que implica a história, o político e a ideologia e que nos permite, assim, pensar a materialidade do espaço, cuja forma, para mim, é a da mobilidade.

\title{
Mobilidade e dispositivos urbanos digitais
}

O que é a mobilidade pensada nessa ordem simbólica e política a que nos referimos: essa ordem do discurso digital? Em outras palavras, quais seriam os movimentos da cidade conectada? Movimentos políticos, sociais, urbanos, culturais, mas também, movimentos dos corpos no espaço geográfico. Movimentos dos sentidos, dos saberes e dos dizeres.

\footnotetext{
${ }^{3}$ Disponível em: http://olhardigital.uol.com.br/video/projeto-usa-tecnologia-aberta-para-reaproveitar-osorelhoes-de-sp/63077
} 
Os trajetos e as localidades urbanas são, também, trajetos políticos. Assim, o movimento dos sujeitos no espaço urbano é também um dis-curso. Des-locamento. Sujeitos e o espaço se significam ao mesmo tempo. Sujeito da favela, sujeito da zona sul, morador do condomínio fechado ou morador de rua, sujeito do campo, sujeito da metrópole, e assim por diante. São sujeitos significados pelo modo como o espaço é politicamente dividido e significado discursivamente, discursos que qualificam os espaços e lhes atribuem funções específicas, modos de vida específicos. Favela, zona sul, condomínio fechado, rua, campo, metrópole. Cada um desses significantes produz um imaginário sobre o sujeito que passa a encarnar sua identidade de sujeito urbano. Essa identidade se fixa aos lugares onde vive e demarca seus percursos possíveis ou interditados. Um morador de rua não pode/deve entrar no condomínio fechado. $\mathrm{O}$ morador da favela não pode/deve ir à praia na zona sul. Conflitos ou estranhamento marcam a transposição dessas fronteiras invisíveis. Tal como podemos ver na notícia publicada em O Dia, em 15/09/2015:

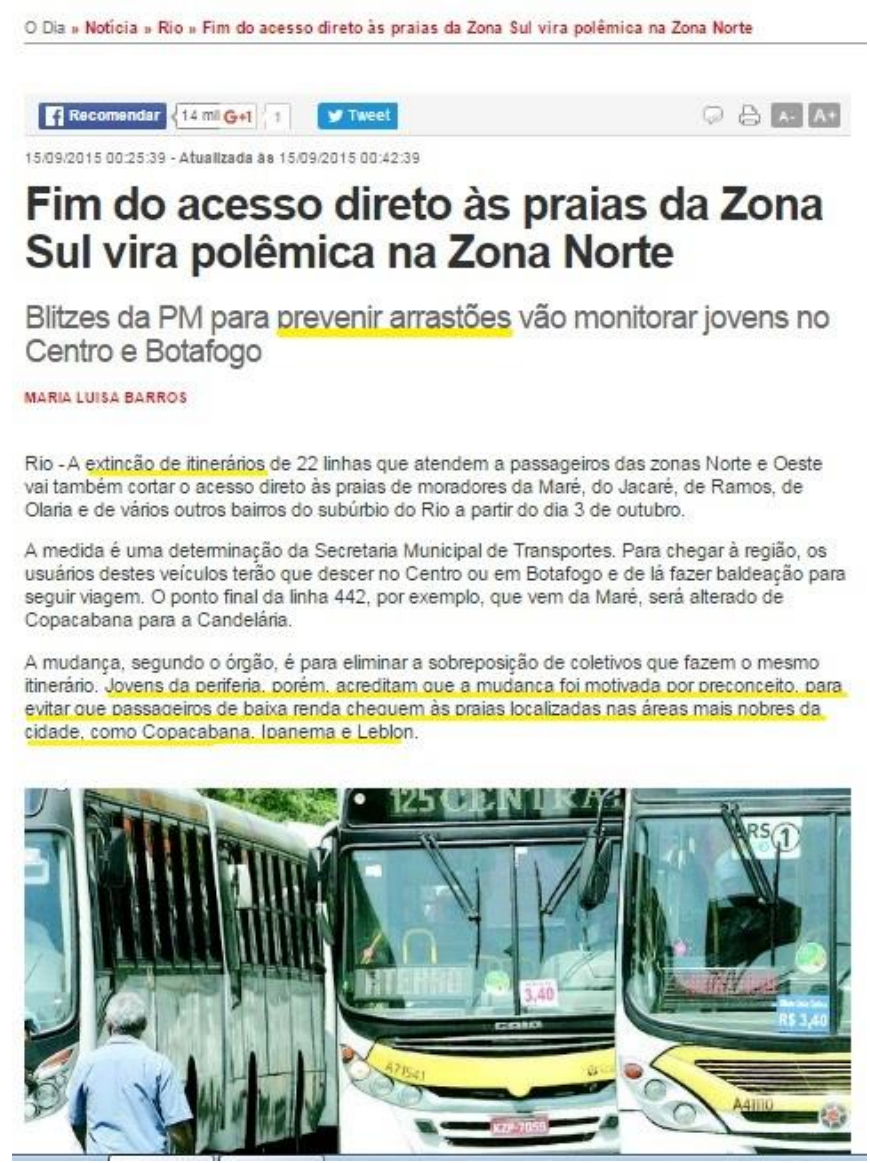

Figura 2 - Captura de tela - Disponível em: http://odia.ig.com.br/noticia/rio-de-janeiro/2015-09-15/fimdo-acesso-direto-as-praias-da-zona-sul-vira-polemica-na-zona-norte.html. Acesso em 12/10/2016 
Espaços divididos: zona sul x zona norte e oeste, Copacabana, Ipanema e Leblon x Maré, Jacaré, Ramos e Olaria. Sentidos divididos: arrastão x proteção (para a zona sul). Sujeitos divididos: jovens do subúrbio, passageiros de baixa renda $\mathrm{x}$ jovens das áreas nobres. Essas fronteiras dizem respeito à mobilidade urbana e são por ela administradas. Esse processo ocorre pela própria administração dos sentidos da circulação, conforme podemos verificar na notícia, na formulação "prevenir arrastões", em destaque. O acesso às praias da zona sul do Rio de Janeiro por moradores de "bairros do subúrbio", já está significado aí pelo sentido de "arrastões", o que justifica, como "medida de prevenção" a “extinção de itinerários” para dificultar o acesso dos jovens da periferia à essas praias por meio do transporte público.
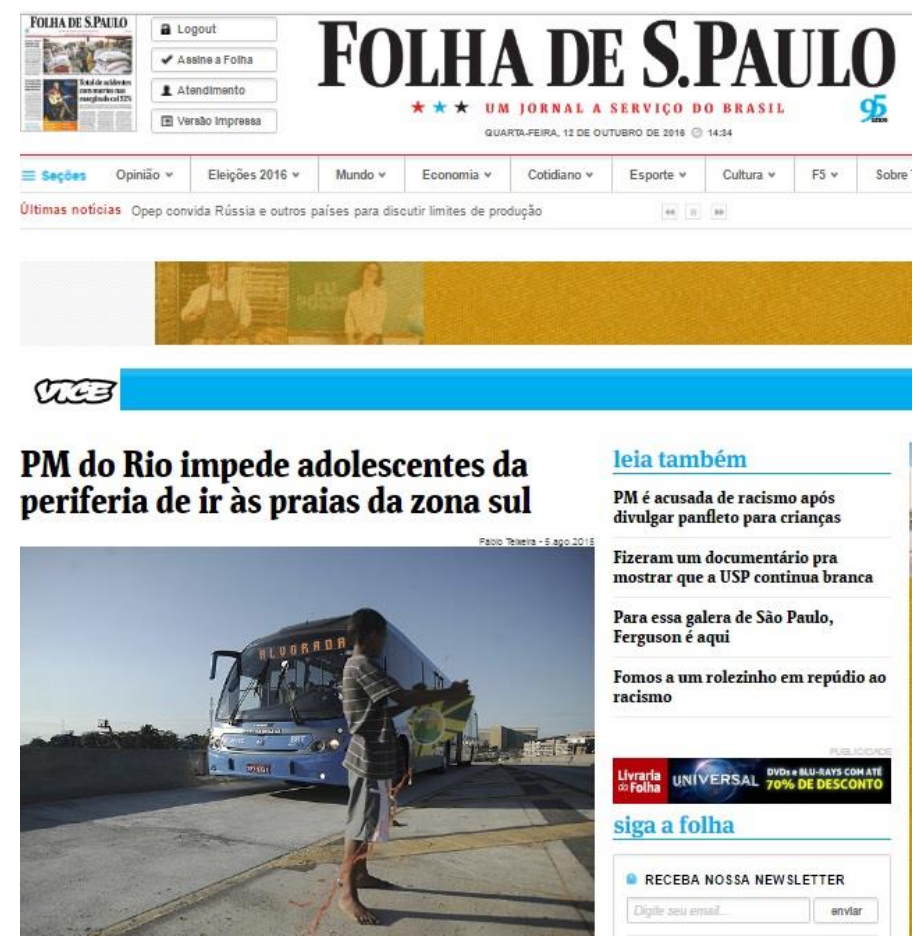

Figura 3 - Captura de tela - Disponível em: http://www1.folha.uol.com.br/vice/2015/08/1673548-pm-dorio-impede-adolescentes-da-periferia-de-ir-as-praias-da-zona-sul.shtml. Acesso em 12/10/2016

Na notícia anterior vemos como a oposição periferia e zona sul significa diferentemente "adolescentes", na medida em que significa pelo não-dito que os "adolescentes" da zona sul podem ir às praias. Em outros termos, o sentido de adolescente morador da zona sul é diferente do sentido de adolescente morador da periferia. E essa diferença regula sua circulação na cidade pela “extinção de itinerários” ou reorganização dos trajetos. A ausência de linhas de transporte público ligando certas regiões das cidades faz parte dos modos de regulação da circulação dos sujeitos, de cerceamento da mobilidade. 
Com a internet não é diferente. Embora se diga que a internet elimina as fronteiras, o fato é que as fronteiras apenas são outras, mas continuam dividindo os sujeitos em espaços politicamente significados.

Se a mobilidade digital se organiza pelo acesso a redes de conexão (seja sem fio ou banda larga) e a infraestruturas de rede, é pelas formas de distribuição dessas redes que as linhas divisórias se estabelecem e que o sentido de mobilidade vai se configurando na relação com as condições de produção, deslocando, assim, a ordem do discurso urbano, da qual o conflito, o movimento, a ruptura e a resistência são parte.

Não é à toa que nos conflitos da Primavera Árabe, em 2011, a Internet saiu do ar e as redes sociais Facebook e Twitter foram bloqueadas. Fazê-lo, é uma maneira de impedir a conectividade, que naquela conjuntura significava a forma de organização da manifestação. A desconexão é, no mundo contemporâneo, uma das maneiras de impedir a multidão ou o encontro.

É nesse “jogo de força da memória” (PECHEUX, 1999, p. 53) entre o movimento e a estabilização, entre a liberdade de ir e vir e a repressão, que o sentido da conectividade vai se constituindo ora pela manutenção da regularização discursiva, negociando seu próprio acontecimento, conformando-se aos sentidos pré-existentes das formas de mobilidade, ora perturbando essa rede de implícitos por ela veiculada, desmanchando a regularização (PECHEUX, 1999, p 52-53), conforme veremos mais adiante a partir da análise do funcionamento da colaboratividade no discurso digital.

O sentido, pois, pensado da perspectiva do político, é dirigido, tem uma direção, mas essa direção diz respeito à ordem simbólica (a sistematicidade sujeita a equívoco), na relação com o real. Como diz Orlandi (2013, p. 06), "a partir do princípio discursivo do trabalho do político, levamos em conta o fato de que o sentido é sempre dividido, tendo uma direção que se especifica na história, pelo mecanismo ideológico de sua constituição". Enquanto produção simbólica, o sentido é uma inscrição do sujeito no mundo, no muro, na folha em branco, na(s) tela(s). Da perspectiva urbanista do espaço, o sentido é também direção, mas diz respeito à organização, refere ao empírico e ao imaginário (o arranjo das unidades) (cf. ORLANDI, 1996) da orientação do sujeito no espaço, como, por exemplo, "ir para o sentido norte ou sul", "virar à direita ou à esquerda".

O movimento, aqui, é pensado, sempre, como político. E o espaço da cidade como textualização desse político: discurso. Em seus des-locamentos, mas também no que se refere aos dispositivos e aos meios utilizados para esses des-locamentos: meios de 
transporte (trem, ônibus, automóvel, metrô, bicicleta, etc.); ou meios tecnológicos (smarthphone, tablet, notebook, pc, etc.).

Com os discursos da sustentabilidade ${ }^{4}$ e da desigualdade de acesso, seja aos serviços, ao poder aquisitivo, aos objetos ou às redes de conexão, esses meios se tornam cada vez mais divisores, significantes dos sujeitos e das sociedades. Quem pode/deve frequentar a praia na zona sul do Rio de Janeiro? Espaços que dividem os sujeitos, por linhas (de transporte, de internet) muitas vezes invisíveis.

Essas linhas e filamentos se estabelecem pelas práticas simbólicas do urbano, naquilo que tece e destece a cidade, a saber, o acaso dos itinerários, os des-locamentos dos sujeitos. O traçado do urbano é feito por sujeitos e seus itinerários algumas vezes não planejadas e que, hoje, passam pela automatização, pelo aplicativo de trânsito ou pelos jogos, como o Pokémon GO, que também divide a cidade e significa os sujeitos determinando-os, marcando-os, pelos lugares onde vivem. Outras vezes ainda esse traçado é determinado pelo próprio discurso da violência na cidade, que pela produção de sentidos do medo e da criminalização, levam os sujeitos a seguir certos itinerários e não outros ou mesmo os obrigam a não ultrapassar as fronteiras invisíveis.

Mas há desvios: um beco, uma passagem que se forma no canteiro, há atalhos. Uma ponte improvisada sobre uma não-passagem. Cidades inteiras construídas no inabitável. Ou destruídas pelo mesmo discurso. Inabitável pelo menos pelo discurso da organização do urbano. A des-ordem da cidade. Dis-curso: relação de sentidos.

É aí que se dá minha entrada no tema que proponho aqui desenvolver através do seguinte questionamento: como podemos pensar o sentido na/da cidade e do sujeito a partir do digital e dos dispositivos móveis? Que desvios são possíveis? De que modo o digital constitui a cidade, produzindo outra ordem e outra organização dos sentidos, perturbando "ao mesmo tempo a ordem do discurso e a organização do social" (ORLANDI, 2004, p. 63)?

Como podemos pensar a "relação" na cidade a partir do sentido de mobilidade como conectividade? É ela possível? Qual a natureza dos vínculos produzidos pela conectividade? Acreditamos que há uma mudança na natureza dos vínculos pelo modo de constituição do sentido do espaço urbano pela conectividade e não pelo encontro aleatório e casual. Embora essa afirmação não negue a existência desses encontros. A questão aqui é apontar para um deslocamento do sentido da relação social, que passa da

\footnotetext{
${ }^{4}$ Sobre essa questão, ver o artigo de Zoppi-Fontana (2011).
} 
convivialidade para conectividade, em seu processo de constituição, e da coletividade para a colaboratividade. Esclareço que essa "passagem" não se dá de forma excludente e nem direta, antes, trata-se da produção de um efeito metafórico, a partir do qual convivialidade e coletividade passam a produzir outros efeitos de sentido, na ordem do discurso digital. Nesse artigo, vou me deter, num primeiro movimento de análise, nos efeitos de sentido produzidos pelo deslize de coletividade para colaboratividade, no que se refere à forma de organização dos sujeitos e dos sentidos de protesto e manifestação. E, num segundo momento, me deterei nos sentidos do "estar junto", produzidos por movimentos urbanos e colaborativos.

Nessa forma da organização (dos movimentos e dos sujeitos), a conexão precede o encontro, o antecipa, o sucede e lhe dá continuidade.

É nesse sentido que apontamos para uma mudança na natureza dos vínculos e dos modos de relação entre os sujeitos, o que dá margem para que um outro tipo de mobilidade produza sentido para a forma de viver o espaço urbano, na "cidade clicável” (CHEVRIER e JUGUET, 2004, p. 73).

O que "linka" os sujeitos uns aos outros no espaço urbano?

\section{Conecticidade}

Perguntar para onde vão os sentidos ou que sentidos para a cidade, é perguntar por um de seus aspectos mais importantes na contemporaneidade, que é a mobilidade. Muito se fala, hoje, em mobilidade, mas o que é a mobilidade e quais são suas características?

Tenho apontado, em meu trabalho (DIAS, 2016), para duas características da mobilidade que são transversais:

\section{- MOBILIDADE DENSA}

\section{- MOBILIDADE RAREFEITA}

A mobilidade densa, consiste no mover-se no espaço físico, de um ponto a outro, seria uma mobilidade onde o corpo e o espaço estão colados, não se separam. Ela diz respeito à organização do espaço, sistematicidade, fixação dos sentidos. Sua textualização no espaço da cidade se dá pela normatização das formas de orientação, como normas de trânsito, legislação sobre a cidade. Essa mobilidade, em suma, normatiza as formas de circulação.

A mobilidade rarefeita diz respeito à mobilidade por meios das redes, ela se textualiza pelo acesso às redes móveis de conexão, o que permite ao sujeito explorar espaços online pelo acesso a sites, informações e aquisição de produtos, visitas a 
localidades, como museus ou bibliotecas online, ou mesmo visitas a espaços urbanos pela tecnologia de mapeamento em 3D, mas também o traçado de itinerários previstos, pelos aplicativos de trânsito. Além disso, a mobilidade rarefeita conecta sujeitos pelas redes sociais, por exemplo, ou por aplicativos de conversa instantânea ${ }^{5}$. A mobilidade rarefeita se dá, pois, pela conectividade e colaboratividade.

Um exemplo do que tenho compreendido como uma relação transversal entre a mobilidade densa e a mobilidade rarefeita diz respeito aos acontecimentos do mês de junho de 2013, no Brasil, marcados por mobilizações em todas as regiões do país. Essas mobilizações foram impulsionadas pela reivindicação ao direito da mobilidade nas ruas (rede de transporte coletivo), no entanto, é a mobilidade rarefeita que articula e expande de forma viral, a manifestação, tanto no momento que a antecede quanto em sua duração, que ultrapassa o momento do ato, na medida em que tem continuidade nas redes sociais pelo compartilhamento de vídeos, imagens e comentários. Como diz o título do capítulo de Leonardo Sakamoto, no livro, Cidades Rebeldes, "Em São Paulo, o Facebook e o Twitter foram às ruas". Mas também, eu diria, as ruas foram ao Facebook e ao Twitter.

Essas manifestações significaram política e transversalmente o espaço apagando suas divisões online - off line. Nas ruas e nas redes era um espaço único que se constituía, o beco era o link, uma passagem clandestina, um fora da organização do urbano.

É preciso destacar a colaboratividade como aquilo que reorganiza o duplo (online $e$ off-line) numa unidade significante. É ela, portanto, um aspecto fundamental da conectividade como significante de mobilidade.

A colaboratividade é um aspecto da vida contemporânea na cidade conectada que mais produz deslocamentos na forma de vida dos sujeitos, na sociedade. Ela seria um filamento de luminosidade, o fio metálico que produz sentido às conexões. A colaboratividade é a lógica da descentralização das redes e plataformas peer to peer.

Se a reivindicação à mobilidade foi o estopim das manifestações de junho de 2013 no Brasil, é pela colaboratividade e conectividade que elas se organizam e difundem. É uma questão política e urbana que teve como forma de organização o espaço digital, onde a colaboratividade, com sua característica descentralizadora, foi fundamental, não apenas pelo compartilhamento intenso dos protestos nas redes sociais, antes, durante e depois de sua realização, mas também pelo uso de ferramentas como o site protestosbr, uma ferramenta de mapa colaborativo que permitiu a atualização constante da situação das

\footnotetext{
${ }^{5}$ Para saber mais sobre a mobilidade rarefeita e a mobilidade densa, ver Dias (2016, p. 157-166).
} 
manifestações nas ruas pelo compartilhamento de informações sobre a polícia, o acesso a serviços, abrigo etc.

Não só nas manifestações de junho de 2013, mas no cotidiano das cidades, a colaboratividade tem sido uma importante característica dos processos de subjetivação do sujeito no espaço urbano e um artefato da mobilidade, por exemplo, através do uso de aplicativos de trânsito, de ônibus, de caronas, de bicicleta, etc. Mas também de encontros, de manifestações sociais e políticas, como vimos.

Mais recentemente, no início do ano de 2016, criou-se também, no Google Maps, o mapa colaborativo das escolas ocupadas contra a Reorganização Escolar, proposta pelo governo do Estado de São Paulo, que propõe a divisão das escolas por ciclo, e em apoio à greve dos professores e por melhorias no sistema escolar, no caso do Rio de Janeiro.

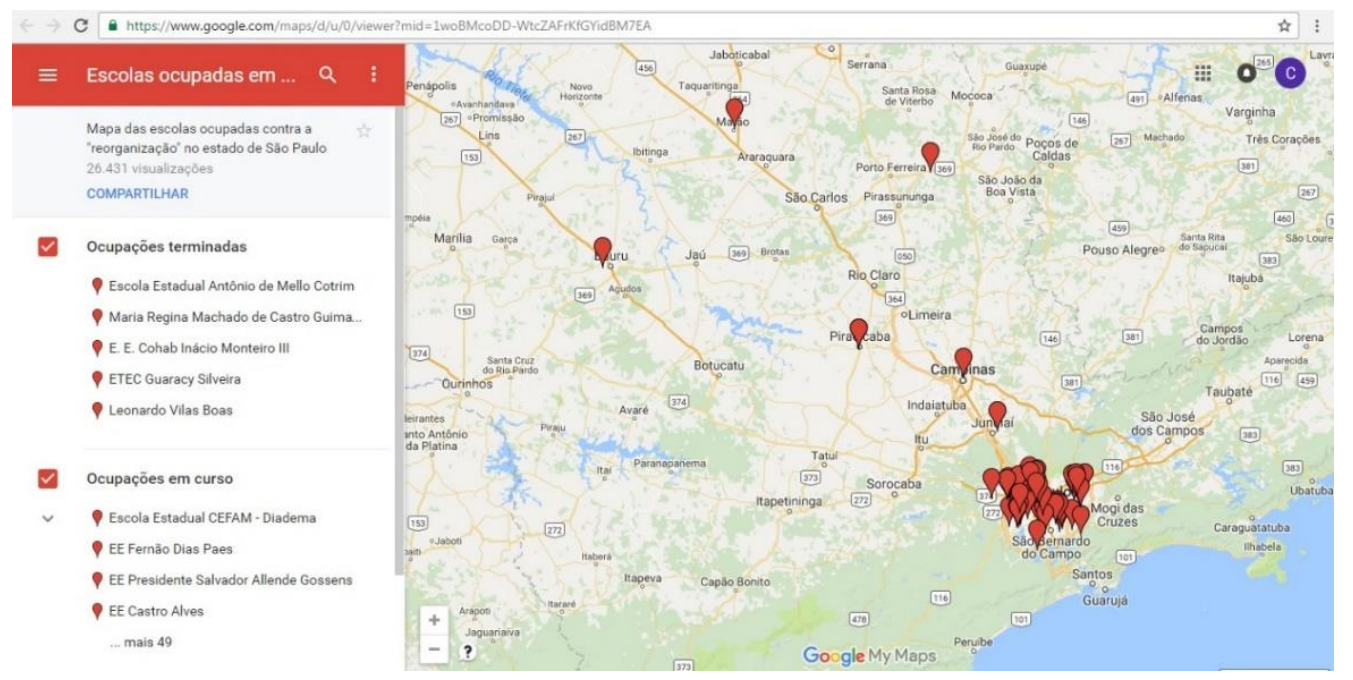

Figura 4 - Mapa colaborativo escolas ocupadas em São Paulo. Disponível em: https://www.google.com/maps/d/u/0/viewer?mid=1 woBMcoDD-WtcZAFrKfGYidBM7EA

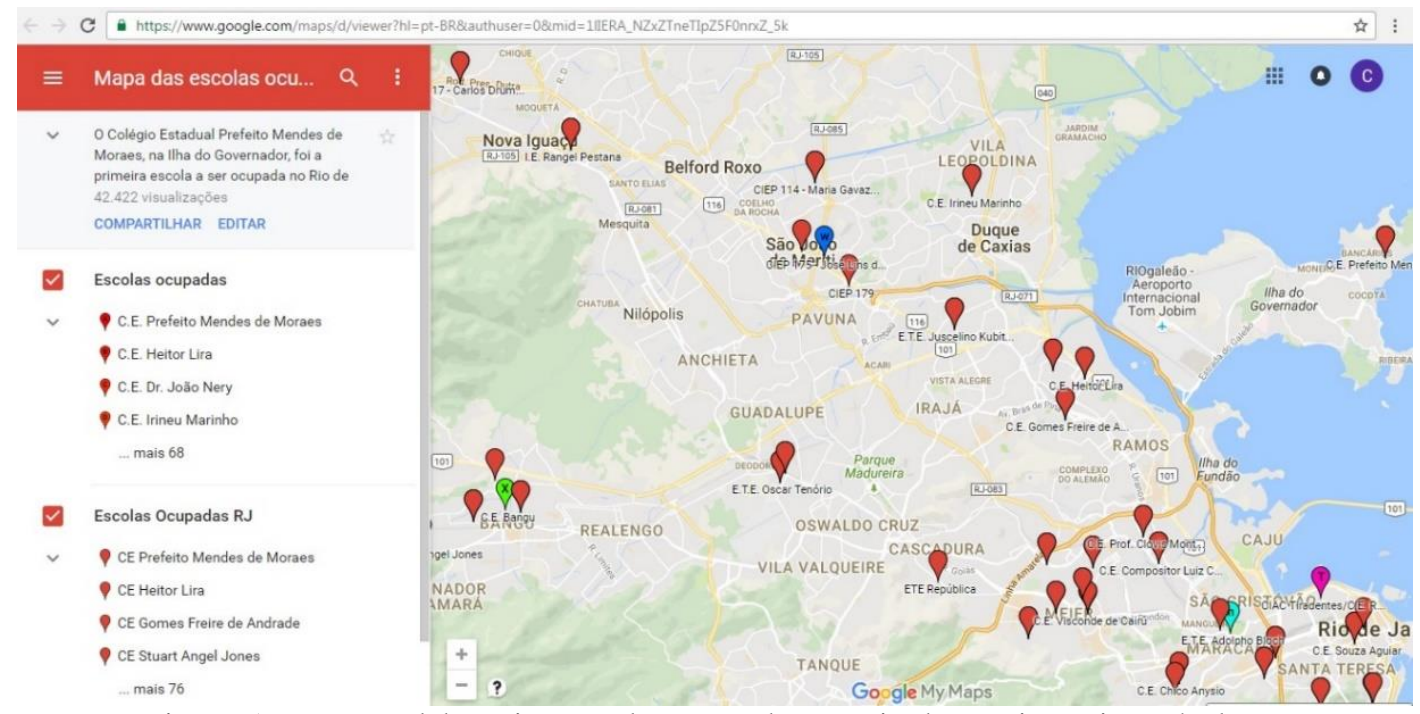

Figura 5 - Mapa colaborativo escolas ocupadas no Rio de Janeiro. Disponível em: https://www.google.com/maps/d/viewer?hl=pt-R\&authuser=0\&mid=11IERA_NZxZTneTIpZ5F0nrxZ_5k 
Esses mapas colaborativos textualizam geograficamente os movimentos políticos das cidades. É nesse sentido que dizemos que a mobilidade é uma questão política e administrativa dos centros urbanos, mas é também uma questão tecnológica e social que diz respeito à forma da sociabilidade contemporânea, ao modo como os sujeitos se juntam, se organizam, fazem laço.

O mesmo recurso ao mapa colaborativo está sendo usado no cenário político mais recente, com o movimento de ocupação das escolas contra a PEC241 - Proposta de Emenda Constitucional do governo Michel Temer, que cria um teto para os gastos público e congela por 20 anos as despesas do Governo Federal.

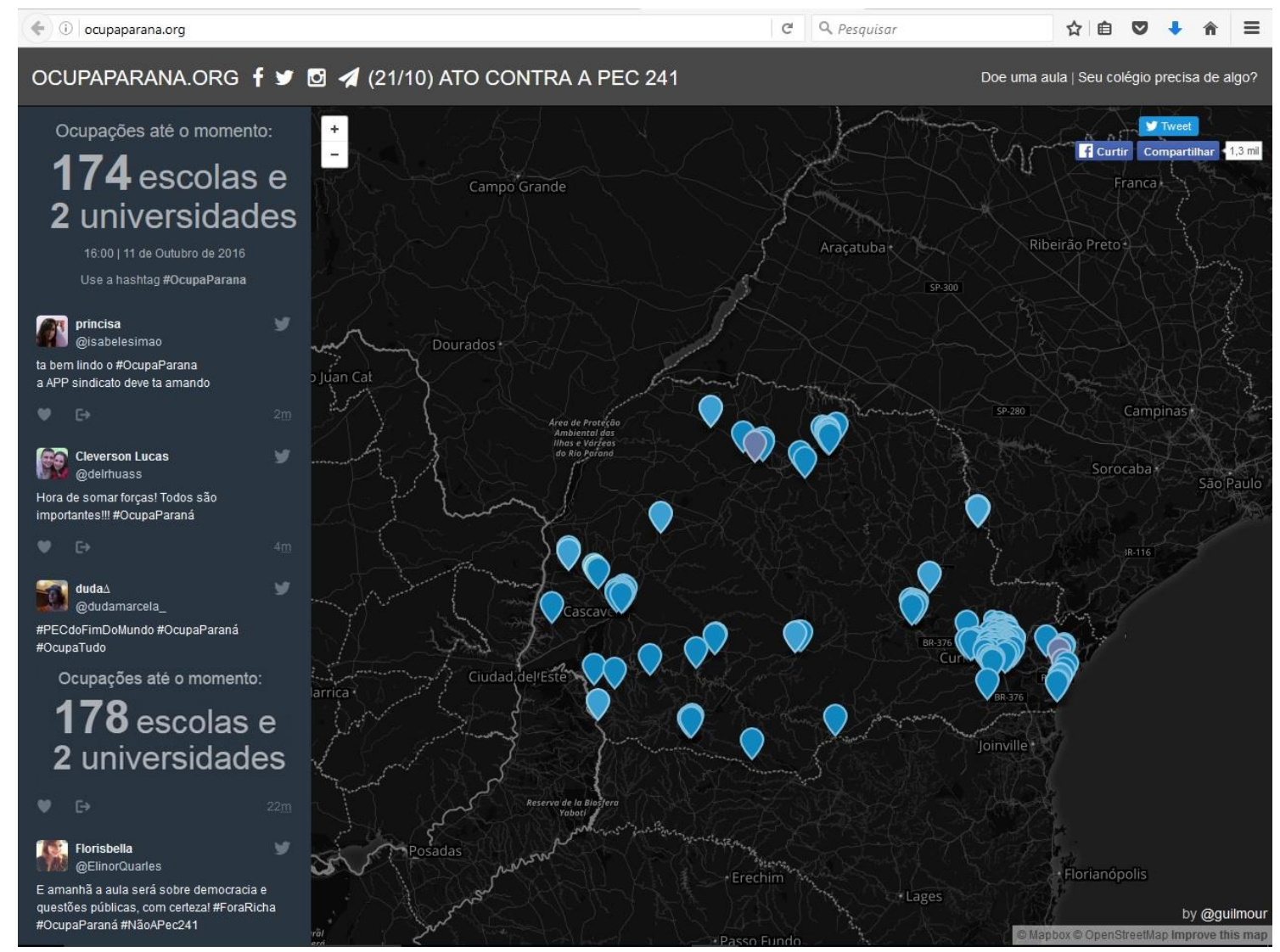

Figura 6 - Mapa da ocupação das escolas do Paraná em outubro de 2016. Disponível em: http://ocupaparana.org/

Esses mapas vão modificando, por um processo de atualização, a representação da geografia da cidade em função dos acontecimentos políticos e sociais. Nesse caso, é um mapa criado através de uma parceria da Mapbox, um serviço de mapas, com a OpenStreetMap, "um projeto de produção colaborativa de dados geo-espaciais abertos" É um mapa editável por qualquer sujeito. Além disso, na imagem, podemos ver, à

${ }^{6}$ http://www.openstreetmap.com.br/ 
esquerda da tela capturada, as postagens do Twitter que são atualizadas cada vez que a \#OcupaParana é utilizada em um tuíte. Desse modo, a colaboratividade ocorre não apenas pela possibilidade de edição do mapa por qualquer sujeito, mas também pelos tuítes de apoio e/ou notícias sobre as ocupações. A colaboratividade também aparece enunciada no canto superior direito da tela capturada: "Doe uma aula/Seu colégio precisa de algo?" Essa formulação apela para os sentidos de colaboratividade, apela para a multidão, para a "contribuição colaborativa" ou, em inglês "crowdsourcing", termo que tem sido muito utilizado na web 2.0, assim como o crowdfunding.

Esse apelo à colaboratividade aponta para alguns sentidos possíveis. Talvez, aqui, o mais premente seja o de uma rejeição ao modo como o sistema educacional brasileiro vem sendo significado. Pedir que alguém "doe" uma aula indica que a escola não está funcionando como deveria e que à revelia do Estado, à revelia da ausência do Estado, ainda assim se busca formas de não sucumbir. Afinal, doa-se aos necessitados, doa-se a quem não tem. Esse apelo coloca em questão, pois, o próprio funcionamento da escola, sua sobrevivência.

\section{Cidade conectada: outros sentidos para mobilidade}

Para os fins da Lei 12.587, de 3 de janeiro de 2012, que institui as diretrizes da política nacional da Mobilidade Urbana, considera-se:

II - mobilidade urbana: condição em que se realizam os deslocamentos de pessoas e cargas no espaço urbano;

No discurso administrativo o sentido de mobilidade é tomado na transparência do que seja o deslocar-se hoje, como se a mobilidade tivesse em si uma neutralidade e uma objetividade. Refere-se à organização do discurso urbano, ao empírico e ao abstrato, como explicita Orlandi (2004, p. 35).

A mobilidade, no entanto, apesar de se constituir na relação com a cidade, como apontamos ao longo desse artigo, não tem necessariamente uma relação consensual com a cidade. Pelo contrário, a mobilidade é aquilo que vai produzir a "desorganização" (ORLANDI, 2004) na cidade, pelo menos para uma "cidade burguesa", com uma ““circulação' estagnada e uma 'mobilização' opressora”, à qual, segundo Lafont (2004, p. 341), os anos 60 e 70 vão se contrapor.

Tenho apontado em meus trabalhos para a opacidade do sentido de mobilidade. Uma noção que historicamente se constitui numa relação de contradição com a cidade. É 
a própria produção de sentido do espaço urbano que produz certas formas de mobilidade. Sendo assim, considerando que com o digital há uma ressignificação do próprio espaço urbano, considero também que a mobilidade assume outras formas. Formas de rede, linhas, filamentos...

Desse modo é preciso perguntar: como os sujeitos se deslocam? Que mapas, trajetos, vias eles produzem? Para onde eles se deslocam?

Se vivemos, hoje, em "cidades conectadas", como fica o sentido da mobilidade? Se, por um lado, frequentemente tratamos de uma mobilidade densa (transportes, infraestrutura, acessibilidade etc.), por outro lado, pouco tratamos da mobilidade rarefeita (redes, conectividade, velocidade), pelo menos, não no que se refere à sua constituição e aos efeitos dessa mobilidade nas formas de sociabilidade, na constituição do urbano.

A questão da mobilidade na cidade conectada é a mobilidade rarefeita.

É no seio dessa problemática que pergunto: como significamos, hoje, o espaço das redes? O que guia nossa mobilidade na cidade? Como tenho dito, na mobilidade rarefeita, o tempo é o espaço de significação (DIAS, 2012). Na velocidade dos $\mathrm{Mb} / \mathrm{s}$ os sujeitos contemporâneos movem-se nas ruas e nas redes, trans-formando o espaço em conectividades acessáveis.

O sentido dessa mobilidade é o acesso, a conectividade.

Mas o que é a conectividade?

Para o Dicionário Priberam ${ }^{7}$, conectividade define-se como sendo:

1. Qualidade do que é conectivo.

2. [Informática] Propriedade ou capacidade que um computador ou um si stema informático tem de se conectar a outros dispositivos.

Partindo dessa definição, vemos que há muitos sentidos silenciados. A conectividade nessa definição não se refere aos sujeitos, pois traz o sentido da informática para significar conectividade. São, pois, os dispositivos e sistemas que se conectam. Não os sujeitos através deles.

Assim, a mobilidade tal com a estou tratando, na relação com a conectividade, também estaria significada pelos sistemas (de transporte, metrô, por exemplo) e tecnologias (redes wi-fi, smartphones, etc.). Trata-se de conectar os dispositivos, mas para

\footnotetext{
7 "conectividade", in Dicionário Priberam da Língua Portuguesa [em linha], 20082013, http://www.priberam.pt/dlpo/conectividade [consultado em 01-11-2015].
} 
que a partir disso a conectividade aconteça no mundo, é preciso que o sujeito esteja aí implicado.

No meu entender, estar conectado é uma forma de mobilidade, porém, com outros contornos e outras paisagens.

A mobilidade, no discurso da administração das cidades, privilegia a conexão entre dispositivos em detrimento da conectividade entre sujeitos. Estou aqui pautada na reflexão de Pechman (2014, p. 35), para o qual o discurso do "fim da cidade", sugerido por alguns urbanistas, consistiria na construção de "um espaço liso e livre de qualquer rugosidade da inconstância humana".

Para o autor, "trata-se, então, de conter os "imbróglios", substituindo relação (desordem) por comunicação (produtividade), objetivando eliminar zonas de fricção que impeçam os fluxos”. Para Pechman (2014), a sociedade em rede seria a amplificação da representação urbana concebida como justaposição e não mais como relação. É aí, justamente, que gostaria de refletir um pouco mais sobre essa suposta possibilidade de substituição de relação por comunicação, pela conectividade.

Se tomarmos a conectividade do ponto de vista da comunicação, infraestrutura, dispositivos, produzimos uma série discursiva que apaga o sujeito e o sentido. Mas se tomarmos a conectividade do ponto de vista da relação, político, laços, simbólico, produzimos uma série que implica necessariamente sujeito e sentido.

Assim, pergunto, que outras possibilidades de sentido (relação a), o surgimento das tecnologias móveis produz para os sujeitos no espaço urbano?

Que possibilidades de relação podemos encontrar na conecticidade por meio dos sistemas e dispositivos? Dispositivos móveis, mas também dispositivos da cidade (vigilância, bancos, cadastros, compras, etc.).

Penso que a relação constitutiva entre o espaço físico e o digital tem muito a nos dizer sobre o "compósito" espaço-corpo-digital, conforme propõe Paveau (2015), pois ele diz respeito à reinvenção dos vínculos, num mundo onde "o trabalho, o comércio, o valor, a cidade, a guerra, a amizade, a identidade, a família - em resumo, a sociedade - se reinventam em torno da mobilidade" (KAPLAN, 2004, p. 13).

Produzir sentidos para o "em comum", como alerta J-Jacques Schaller (Enelin, 2015), é a possibilidade de ressurgimento do político como constitutivo das relações. O “em comum" considera o político e, portanto, aquilo que é próprio das relações: a diferença. Para Orlandi (2013, p. 7, 8), trata-se da "invenção como método e como posse 
do mundo" (...) "a costura da vida [diz Orlandi]. Que se dá ao lado ou apesar das relações sociais".

Assim, faremos das telas passagens abertas sobre espaços inabitáveis por violências de diferentes ordens. Lugares do "em comum", da "invenção da vida", "posse do mundo"!

Eni Orlandi (2013), em sua reflexão sobre a natureza e os sentidos de laço social, "este que une um sujeito a outro na história, laço gerido pelo Estado", aponta que "a base da "relação social", discursivamente está no "outro", pensadas a ligação, a identificação e a transferência (ou seja, a metáfora). Ligam-se assim o social, o histórico e o significante". Tomando essa formulação, proponho pensar o sentido de "relação social" na cidade conectada, mais especificamente a partir do funcionamento do "Vamos juntxs" em projetos e movimentos da Internet, dos quais trago, aqui três exemplos.

O primeiro é o projeto do movimento "Vamos Juntas?", que foi criado por Babi Souza, de 24 anos, com o objetivo de incentivar as mulheres a andarem juntas como forma de inibição da violência contra elas no espaço urbano.

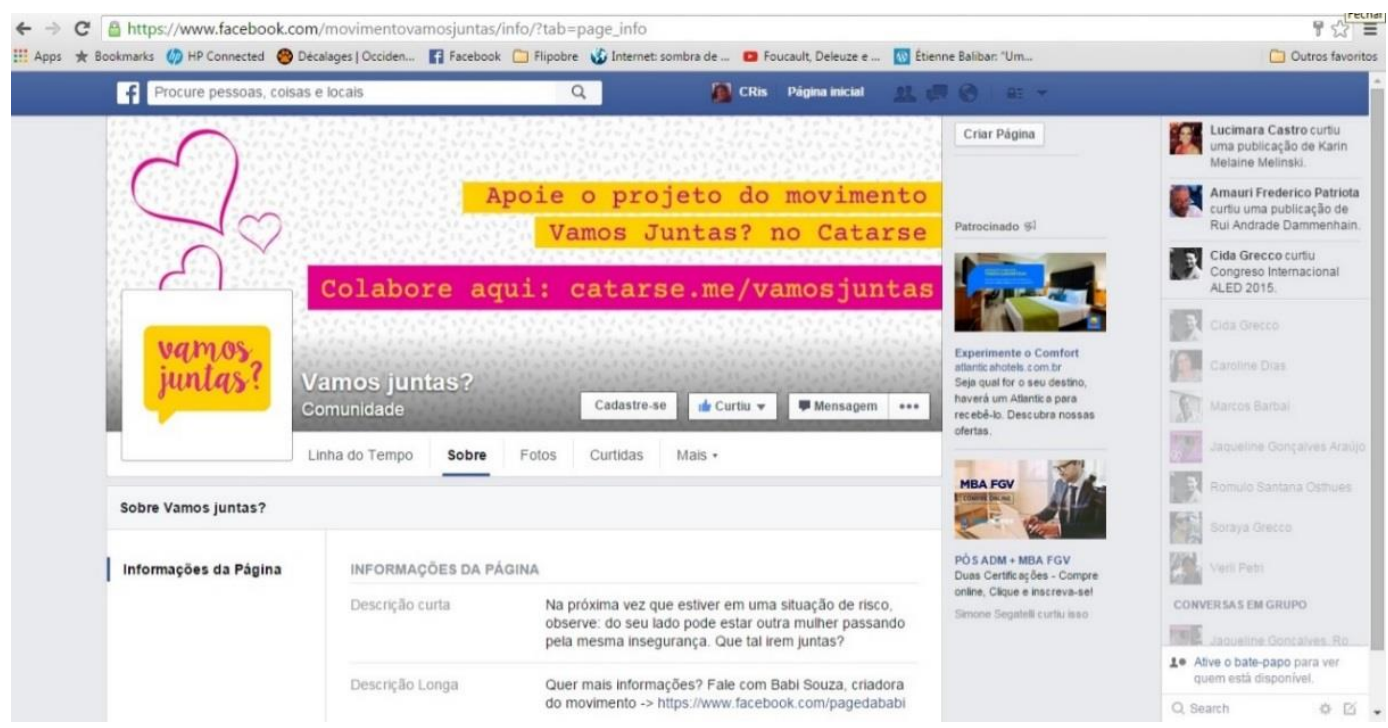

Figura 7 - Captura de tela - https://www.facebook.com/movimentovamosjuntas/?fref=ts

O segundo é o "Vamos Juntos", um grupo de lazer e inclusão social para jovens e adultos com deficiência intelectual.

\footnotetext{
${ }^{8}$ Uma análise mais aprofundada do movimento "Vamos Juntas?" e seus efeitos de sentido, será publicada em El Análisis del Discurso en Latinoamérica, Actas del XI Congreso Internacional ALED (coords. Salvio Martín Menéndez y Alicia E. Carrizo), en Buenos Aires, 2016 (no prelo).
} 


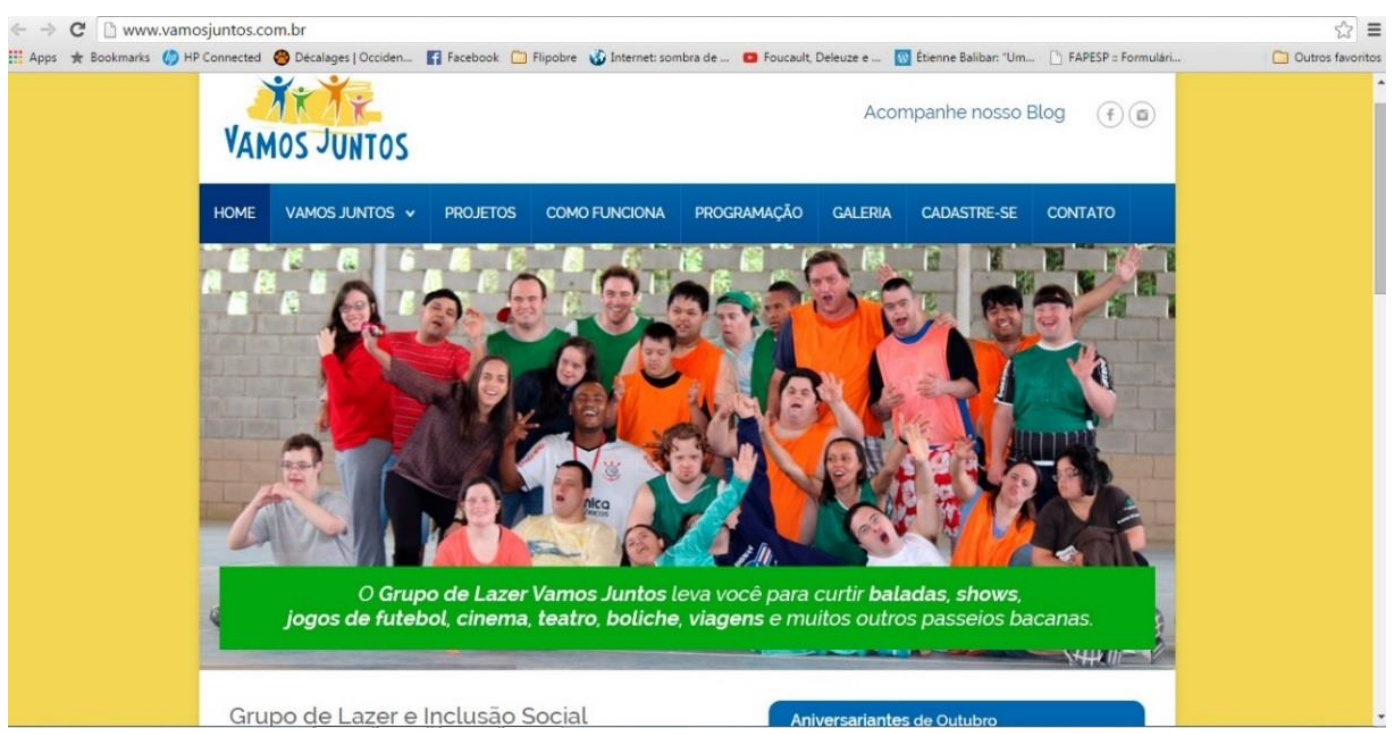

Figura 8 - Captura de tela - http://www.vamosjuntos.com.br/

Temos aí dois diferentes projetos, com objetivos diferenciados, e que põem em funcionamento diferentes sentidos para o "Vamos juntxs", ou seja, diferentes sentidos de grupo, de organização, que tem sua materialidade na conectividade e na colaboratividade. Eles se significam pelo encontro de sujeitos no espaço urbano.

Em ambos está em funcionamento o "em comum”. Colocá-lo em funcionamento vai tecendo, com uma linha invisível de relações e convívio na cidade, que é potente pelo seu teor político, por ressignificar a cidade como lugar de convivência, uma rede capaz de produzir na cidade outros sentidos possíveis. Seja a possibilidade de se deslocar sem medo, seja a possibilidade de se divertir sem preconceito.

Essa rede digital, uma vez que está atravessada pelo sentido da conectividade entre sujeitos, é invisível e capaz de fazer tropeçar a própria violência pautada no fracasso da cidade como esse lugar de convívio, e não de "evitamento" (GAUCHET, 2002). Nada tem a ver com a cidade pacificada, vigiada, lisa, produtiva, onde o medo é, de certa forma, regulador da desordem e dos agrupamentos.

O digital e a mobilidade não são, portanto, os carrascos da cidade, a partir deles os sujeitos inventam a sociedade e outras formas de "estarem juntos". O movimento "Vamos Juntas?" e "Vamos juntos", é uma intervenção no real do sentido, capaz de deslocar conexão, para relação; link, para relações sociais. Capaz de deslocar o próprio sentido de mobilidade. Os dois movimentos, de formas distintas, constituem a cidade, lugares que a própria cidade, no modo como é discursivizada pela violência, o perigo e a hostilidade, impede os sujeitos de significar. E não se trata aqui de um impedimento 
formal, como vimos no caso da extinção das linhas de ônibus para as praias da zona sul, no Rio de Janeiro, mas de um impedimento ideológico.

\section{Palavras finais}

O objetivo desse artigo foi o de compreender a maneira como dispositivos tecnológicos produzem uma outra ordem da cidade, a do discurso digital, e como essa ordem ressignifica o espaço e a maneira de estar nele. Como o social é significado na/pela conectividade? Pelo digital.

Segundo Orlandi (2001, p. 186), "a cidade é injunção a trajetos, a vias, a repartições, a programas, traçados e regulamento." Partindo dessa afirmação, procurei mostrar como esses traçados e trajetos vão se bifurcando com o digital, encontrando outras possibilidades, abrindo outras camadas da cidade e como aí, nesse movimento, as relações digitais se socializam, abrindo outras vias para a produção dos sentidos do público, da rua, da resistência.

\section{Bibliografia}

CHEVRIER, Stéphane, JUGUET, Stéphane. Vers une appropriation numérique de la ville ? In: Kaplan \& D. Lafont, H. (Ed.) Mobilités.net: villes, transports, Technologies face aux nouvelles mobilités. Paris: L.G.D.J, 2004. p. 71-74.

DIAS, Cristiane. A materialidade digital da mobilidade urbana: espaço, tecnologia e discurso. Revista Línguas e Instrumentos Linguísticos. n. 37. Jan./jun. 2016. p. 157175. Disponível em: http://www.revistalinguas.com/edicao37/edicao37.html

Sujeito e tecnologias: o tempo como espaço de significação. In. MALUF-SOUZA, Olímpia et. al. (orgs.). Discurso, sujeito e memória. Campinas, Pontes, 2012.

GAUCHET, Marcel. La démocratie contre elle-même. Paris: Gallimard, 2002.

KAPLAN, Daniel. Préface. In: Kaplan \& D. Lafont, H. (Ed.) Mobilités.net: villes, transports, Technologies face aux nouvelles mobilités. Paris: L.G.D.J, 2004. p. 13-15.

LAFONT, H. A propos de "nomades et vagabonds". In: Kaplan \& D. Lafont, H. (Ed.) Mobilités.net: villes, transports, Technologies face aux nouvelles mobilités. Paris: L.G.D.J, 2004.

ORLANDI, Eni. No leva-e-traz da política científica. In. Revista Rua. Edição Especial 20 anos. 2014, p. 6-14. Disponível em: www.labeurb.unicamp.br/rua

ORLANDI, Eni. Cidade dos sentidos. Campinas: Pontes, 2004.

No limiar da cidade. Revista Rua, volume (1), 1999, p. 07-19. Disponível em: http://periodicos.sbu.unicamp.br/ojs/index.php/rua/issue/view/699/showToc

Interpretação: autoria, leitura e efeitos do trabalho simbólico. 2 ed. Petrópolis: Vozes, 1996. 
PAVEAU, Marie-Anne. Linguagem e moral: uma ética das virtudes discursivas. Trad. Ivone Benedetti. Campinas: Editora da Unicamp, 2015.

PÊCHEUX, Michel. (1999). Papel da Memória. In: Achard, P. et. al. Papel da Memória. Trad. José Horta Nunes. Campinas: Pontes.

PECHMAN, Robert. Quando Hannah Arendt vai à cidade e se encontra com Rubem Fonseca: ou da cidade, da violência, da política. In: Kuster, E. e Pechman, R. O chamado da cidade: ensaios sobre a urbanidade. Belo Horizonte: Editora UFMG, 2014.

SCHALLER, J. (2015). Fabriquer de l'espoir au bord du gouffre: Changeons de boussole! Conferência ministrada no V Encontro Internacional de Estudos da Linguagem - Enelin. Pouso Alegre.

ZOPPI-FONTANA, Mónica. A cidade se mexe: da bicicleta ao cycle chic. In. Cadernos de Estudos Linguísticos. Vol. 53, n. 2, 2011.pp. 179-196. 


\section{Para citar essa obra:}

DIAS. Cristiane, Linhas, redes e filamentos: no fio do discurso da cidade In: RUA [online]. Especial: Cidade Conectada p. 259-277 - ISSN 1413-2109/e-ISSN 2179-9911 - outubro/2016. Consultada no Portal Labeurb - Revista do Laboratório de Estudos Urbanos do Núcleo de Desenvolvimento da Criatividade.

http://www.labeurb.unicamp.br/rua/

Capa: Figura 8 - Captura de tela - http://www.vamosjuntos.com.br/

Laboratório de Estudos Urbanos - LABEURB

Núcleo de Desenvolvimento da Criatividade - NUDECRI

Universidade Estadual de Campinas - UNICAMP

http://www.labeurb.unicamp.br/

Endereço:

LABEURB - LABORATÓRIO DE ESTUDOS URBANOS

UNICAMP/COCEN / NUDECRI

CAIXA POSTAL 6166

Campinas/SP - Brasil

CEP 13083-892

Fone/ Fax: (19) 3521-7900

Contato: http://www.labeurb.unicamp.br/contato 